\title{
Modeling soundscape pleasantness using perceptual assessments and acoustic measurements along paths in urban context
}

\author{
Pierre Aumond ${ }^{\mathrm{a}}$, Arnaud Can ${ }^{\mathrm{b}}$, Bert De Coensel ${ }^{\mathrm{c}}$, Dick Botteldooren ${ }^{\mathrm{c}}$, Carlos Ribeiro ${ }^{\mathrm{d}}$, \\ Catherine Lavandier ${ }^{\mathrm{a}}$ \\ ${ }^{a}$ ETIS, CNRS UMR8051, ENSEA, Université de Cergy-Pontoise, France \\ ${ }^{b}$ Ifsttar, AME-LAE (Laboratoire d'Acoustique Environnementale), F-44341 Bouguenais, France \\ ${ }^{c}$ Waves Research Group, Department of Information Technology, Ghent University, Technologiepark-Zwijnaarde 15, B-9052 Ghent \\ ${ }^{d}$ Bruitparif, France
}

\begin{abstract}
Mapping the pleasantness of an urban environment is an alternative approach, closer to the city dweller's perception, than standardized sound levels cartography. This study reports on modeling pleasantness in urban context using perceptual assessments and sound measurements for specific locations during an urban walk. These assessments have been collected from four groups of approximately ten participants on 19 different assessment locations, along a 2,1 km-long path traveled in both directions. Simultaneously, $1 / 3$ octave band sound levels and audio were recorded. Perceptual and physical models of pleasantness are proposed for specific locations based on multiple linear regressions. A multilevel analysis was performed, and it is shown that a perceptual model that includes perceived loudness joined to the perceived time of presence of traffic, voices and birds explains $90 \%$ of the pleasantness variance due to the sound environment variations. Physical models that include the original acoustic indicators that are most correlated with perceptual variables explain $85 \%$ of this variance. Thanks to these models, a unique averaged pleasantness value is defined for each assessment location from the perceptual or physical collected assessments. The Pearson's correlation coefficient between the averaged perceived pleasantness and the modeled values from perceptual assessment reaches $r(19)=0.98$, and $r(19)=0.97$, with the modeled values from physical measurements. These results make it possible to consider the use of this kind of models in a cartographic context. As the path was traveled in both directions, the presentation-order effect has also been assessed, and it has been found that path direction did not have a significant impact on the pleasantness assessment at specific locations, except when very strong sound environment changes occurred. Finally, the study gives some insights about the retrospective global pleasantness assessment for urban walks. For very short walks between two assessment locations, a recency effect is shown. Nevertheless, this effect doesn't seem to be significant when longer routes are assessed.
\end{abstract}

Keywords: Soundscape; Sound environment; Pleasantness; Urban walk;

\section{Introduction}

The increasing urbanization results in the deterioration of urban sound environments. Noise is regularly cited by city dwellers as the principal cause of annoyance. To fight against this nuisance, the European Directive 2002/49/CE requires cities of more than 100000 inhabitants to develop and publish strategic noise maps [1]. The role of the produced maps is to help decision makers in the development of noise mitigation plans and to inform city dwellers about their exposure. However, since these noise maps are usually based on a modeling chain that only accounts for a limited set of sound sources, namely road traffic, railway traffic, aircraft and major industries, they hardly represent the richness of urban sound environments. The specificity of noise pollution lies in the variety of sound sources, the high spatiotemporal and rich spectral variations in sound, and the complexity of human hearing.

Several recent studies showed that the usual energy-equivalent sound indicators fail to describe the complexity of urban soundscapes and that they cannot capture the perception that city dwellers have of their sound environment [2]-[5]. Accordingly, alternative approaches are under development, which rely on novel indicators for sound mapping. These approaches are closer to the city dweller's perception, and as such are better descriptors of soundscape quality [2], [6]-[8]. A key point when assessing the quality of urban sound environments is therefore the selection of relevant descriptors that are correlated to perceptual dimensions, which should be easy to understand and handle [9]. 
It is acknowledged that the quality of sound environments can be characterized by perceptual parameters [8], [10], [11]. These perceptual parameters can focus on the sound sources that compose the urban soundscape, such as traffic, humans or natural elements, and may describe their time of presence, sound level, or dominance [8], [10]-[12]. Studies report a consensus about the positive contribution of natural sounds and the negative contribution of traffic sounds to soundscape quality, whereas the contribution of human sounds can be either positive or negative. Other approaches focus instead on holistic notions, such as loudness, calmness, liveliness, annoyance, etc. [11]. In that line, the notion of perceived pleasantness proved particularly relevant to assess the quality of sound environments, and thus receives increasing attention [2], [13]-[15]. Consequently, recent models aimed to predict the pleasantness of the sound environment based on perceptual parameters typically account for the time of presence of sound sources [8], [16]. Finally, factors non-related to the sound, such as visual parameters [17] or others external factors [17]-[20], can also affect the perceived soundscape quality.

However, although very meaningful, models based on perceptual parameters often have a low practical potential in a cartography context, since they require prior in situ perceptual tests. Also, during the last decade, various studies focused on characterizing the quality of sound environments directly from acoustics measurements [4], [10], [12], [16], [21], [22]. These approaches are encouraged by novel acoustic mapping techniques based on low-cost sensor networks, or participative measurements, which allow obtaining sound maps with a higher spatial resolution, while being sensitive to all kind of sound sources constituting the sound environment [23]-[26]. Studies linking perceptual tests to acoustical measurements showed for instance that better estimates of the pleasantness of sound environments are obtained if parameters describing the temporal variations of sound, the sound spectrum, or the contributions of specific sound sources, are introduced in the modeling [8], [10], [27], [28]. In addition, physical indicators such as $\mathrm{L}_{50}, \mathrm{~L}_{\mathrm{eq}}$ or Zwicker's Loudness are most of the time well correlated to the pleasantness or the perceived loudness [8], [11], [29], [30]. Predictions can finally be improved by introducing others indicators such as the level variability over time and the proportion of low-frequency sounds [31], [32].

Although instructive, these approaches differ from the city dweller's experience of the urban sound environment during walking trips. Being able to estimate the exposure associated to an urban walking trip has many potential interests, such as for informing pedestrians about the potential restorative capacity or even health benefit of their intended walk. To date, only few studies are available that investigated how outdoor soundscapes are assessed over time [33]-[35], and these studies show that recency or presentation-order effects can be observed during transitions between different sound environments [36]. Likewise, only few studies investigated the temporal dynamics of sound environments and their assessment [33].

In this paper, models are proposed to estimate the pleasantness of sound environments along paths in urban context, travelled in both directions. The models are based on an in situ sound walk. Along the pathway, the participants filled in a questionnaire about the sound environment at 19 assessment locations. The proposed methodology, based on an in situ questionnaire survey, follows a protocol already shared by other soundscape studies listed in Aletta et al [2]. In addition, the questionnaire included questions about the sound environment perceived between the assessment locations, and questions about the global pleasantness of the walking trip. Results are discussed in relation to the sound pleasantness model proposed by Ricciardi et al. which is based on the same parameters and a similar methodology [8]. These similarities with previous studies will allow testing the robustness of the perceptual models developed in this work over the different time frames investigated.

The aim of this research is threefold: 
(1) To propose models of perceived pleasantness based on perceptual properties or acoustic indicators, in order to characterize soundscape quality along a walking path in an urban context.

(2) To study the presentation-order effect of assessment locations along a walking path in an urban context, that is, whether or not the order in which the participants visit a set of locations affects how they assess them.

(3) To study the relationships between local and overall assessment of a walking path in an urban context.

\section{Method}

\subsection{Study area and chosen pathway}

The study consisted of a perceptual test performed 4 times (referred further as "study sessions" in the text) over a $2,1 \mathrm{~km}$-long path, located in Paris $\left(13^{\text {th }}\right.$ district). Assessments were done on 19 locations (referred further as "assessment locations" in the text) located along the path, with an average distance of 115 meters between locations. Figure 1 presents the chosen path for the test and the different assessment locations along this path.

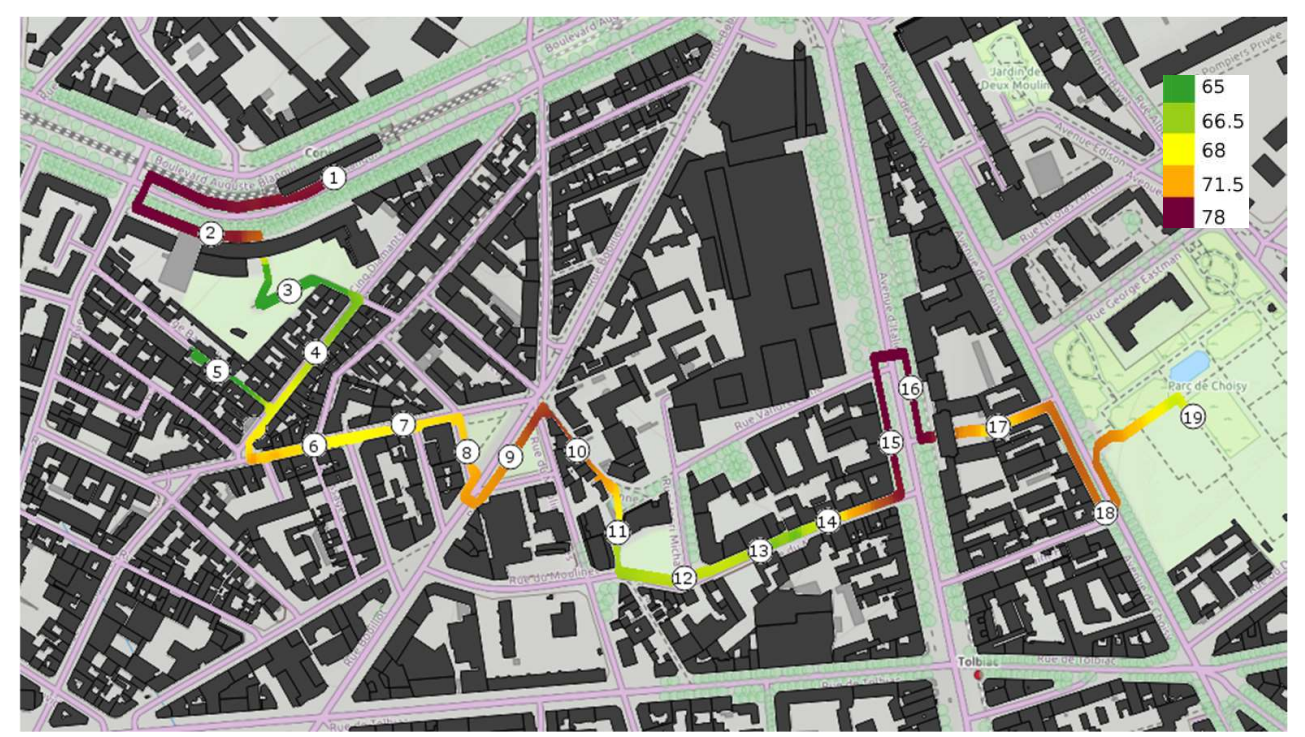

Figure 1 Sound map of the studied path, interpolated from mobile measurements (Leq - dB). The points 1 to 19 correspond to the different assessment locations.

Table 1 gives a brief description of the sound environments and the approximate traffic flow rate at each assessment location (data from the Paris City Hall - Green Spaces and Environment Department). As shown in Table 1 and Figure 1, the assessment locations were chosen to contain a large variety of urban sound environments, and the path was chosen to contain multiple changes in the sound environment, both smooth and sudden.

Table 1 Description of the assessment locations along with approximate vehicle flow rates

\begin{tabular}{|lll|lll|}
\hline $\begin{array}{l}\text { Assessment } \\
\text { Location }\end{array}$ & Morphology & $\begin{array}{l}\text { Flow } \\
\text { Rate } \\
{[\text { Veh/h] }}\end{array}$ & $\begin{array}{l}\text { Assessment } \\
\text { Location }\end{array}$ & Morphology & $\begin{array}{l}\text { Flow } \\
\text { Rate } \\
\text { [Veh/h] }\end{array}$ \\
\hline P1 & Large two-lanes traffic street & $\sim 2 \times 750$ & $\mathbf{P 1 1}$ & Quiet street without traffic & \\
P2 & Large two-lanes traffic street & $\sim 2 \times 750$ & $\mathbf{P 1 2}$ & Street with very low traffic flow rates & $\sim 50$ \\
P3 & Quiet park & P13 & Street with very low traffic flow rates & $\sim 50$ \\
\hline
\end{tabular}




\begin{tabular}{|lll|ll|}
\hline P4 & Animated street (Bars \& Restaurants) & $\sim 50$ & P14 & $\begin{array}{l}\text { Street with very low traffic flow rates } \\
\text { P5 }\end{array}$ \\
$\begin{array}{llll}\text { Very quiet street with rare traffic pass- } \\
\text { byes, }\end{array}$ & $\sim 10$ & P15 & $\begin{array}{l}\text { Street with high vehicle flow rates } \\
\sim 2000\end{array}$ \\
P7 & Animated street (Bars \& Restaurants) & $\sim 50$ & $\mathbf{P 1 6}$ & $\begin{array}{l}\text { Street with high vehicle flow rates } \\
\text { Quiet pedestrian street located between two } \\
\text { busy street }\end{array}$ \\
P8 & Animated street (Bars \& Restaurants) & $\sim 50$ & P17 & Street with interrupted traffic (traffic lights) \\
P9 & Park alongside a street & $\sim 750$ & P18 & Large Park \\
P10 & Street with moderate traffic flow rates & $\sim 750$ & P19 & \\
\hline
\end{tabular}

\subsection{Participants}

In total 37 participants performed the walks ( 25 men, 12 women; 23 from 10-29 y.o, 8 from 30-39 y.o, 2 from 40-49 y.o, 3 from 50-59 y.o, 1 from 60-75 y.o). Participants were recruited from outside of the university. They were divided into four study sessions, with about 10 participants per session (the exact number per session is given in Table 3), which is small enough to not modify the surrounding sound environment, while keeping a sufficient number to perform statistical analysis. The participants took part in only one of the four study sessions, and received a small monetary compensation.

\subsection{Equipment}

Sound levels were measured continuously during each study session, using a dedicated sound measurement station developed by ASAsense, carried by an operator that followed the group. The devices were tailored for mobile measurements, being mounted in a backpack. The microphone was placed over the head of the operator, to ensure the omni-directionality of measurements, and was powered by a battery pack [3]. Figure 2 presents the sound measurements station inserted in the backpack used by operators. Instantaneous 1/3-octave band levels were recorded with a 125 ms-temporal resolution, simultaneously with GPS synchronized 1s-position data, so that the space and time evolution during any study session could be reconstructed in full afterwards. Audio signals were simultaneously recorded by the device.

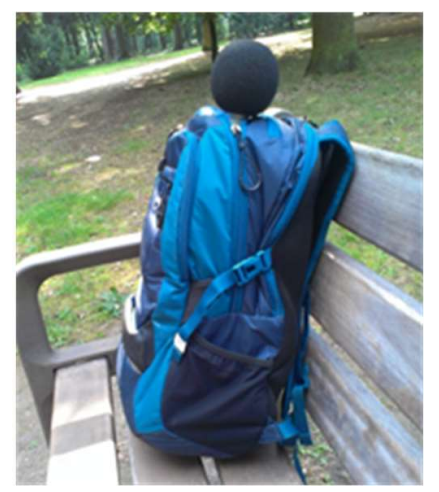

Figure 2 Backpacked sound measurement station.

In order to fully capture the sound environment characteristics, a very large set of indicators $(n=480)$ has been calculated. Table 2 presents an overview of the acoustical indicators extracted from the measurements. Some indicators were calculated for two integration times ( $1 \mathrm{~s}$. and $125 \mathrm{~ms}$.), two spectral weightings (Linear and A-weighted), and various statistical descriptors are calculated using energetic or arithmetic averaging, standard deviation, and percentiles. The indicators were calculated on the basis of the global sound level, but in some cases also for each octave band from $31.5 \mathrm{~Hz}$ to $16 \mathrm{kHz}$. 
Table 2 Summary of the set of indicators $(n=480)$ extracted from the measurements.

\begin{tabular}{|c|c|c|c|c|c|c|c|c|c|}
\hline \multirow[b]{2}{*}{ Abbreviation } & \multirow[b]{2}{*}{ Description } & \multicolumn{2}{|c|}{$\begin{array}{l}\text { Integration } \\
\text { time }\end{array}$} & \multicolumn{2}{|c|}{ Ponderation } & \multirow[b]{2}{*}{ Average } & \multirow[b]{2}{*}{$\begin{array}{c}\text { Standar } \\
\text { d } \\
\text { deviatio } \\
\mathbf{n}\end{array}$} & \multirow[b]{2}{*}{$\begin{array}{c}\text { Min, Max } \\
\text { Percentiles } \\
(1,5,10,50 \text {, } \\
90,95,99)\end{array}$} & \multirow[b]{2}{*}{$\begin{array}{c}\begin{array}{c}\text { Octave } \\
\text { band } \\
\text { from }\end{array} \\
31.5 \mathrm{~Hz} \text { to } \\
16 \mathrm{kHz}\end{array}$} \\
\hline & & & $125 \mathrm{~ms}$ & $\begin{array}{c}\text { Linear } \\
\text { ponderation }\end{array}$ & A ponderation & & & & \\
\hline $\mathbf{L}$ & Sound pressure level & $\mathrm{x}$ & $\mathrm{x}$ & $\mathrm{x}$ & $\mathrm{x}$ & Equivalent (Leq) & $\mathrm{x}$ & $\mathrm{x}$ & $\mathrm{x}$ \\
\hline $\mathbf{N}$ & $\begin{array}{l}\text { Zwicker loudness } \\
\text { (sone), (ISO 532 B) }\end{array}$ & $\mathrm{x}$ & $\mathrm{x}$ & & & & & $\mathrm{x}$ & \\
\hline $\begin{array}{c}\mathrm{L}_{10-} \mathrm{L}_{90}, \mathrm{~L}_{5-95} \\
\mathrm{~N}_{10-\mathrm{N}_{90}, \sigma}\end{array}$ & $\begin{array}{l}\text { Dispersion parameters } \\
\sigma: \text { standard deviation } \\
\text { of sound pressure level }\end{array}$ & $\mathrm{x}$ & $\mathrm{x}$ & $\mathrm{x}$ & $\mathrm{x}$ & & & & $\mathrm{x}$ \\
\hline $\begin{array}{l}\mathrm{CoG}_{32 \mathrm{~Hz}-8 \mathrm{kkH}} \\
\mathrm{CoG}_{125 \mathrm{~Hz}-8 \mathrm{kH}} \\
\mathrm{CoG}_{32 \mathrm{~Hz}-16 \mathrm{kHz}}\end{array}$ & $\begin{array}{c}\text { Spectrum center of } \\
\text { gravity }\end{array}$ & $\mathrm{x}$ & & $\mathrm{x}$ & & Arithmetical & & $\mathrm{x}$ & \\
\hline 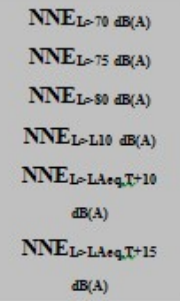 & $\begin{array}{l}\text { Number of Noise } \\
\text { Events }\end{array}$ & $\mathrm{x}$ & & & $\mathrm{x}$ & & & & \\
\hline 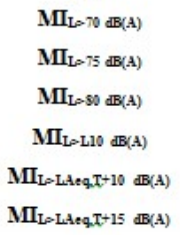 & $\begin{array}{c}\text { Mask Index } \\
\text { (cumulative time during } \\
\text { which thresholds are } \\
\text { exceeded) }\end{array}$ & $\mathrm{x}$ & & & $\mathrm{x}$ & & & & \\
\hline TFSD & See Equation 1 & $\mathrm{x}$ & $\mathrm{x}$ & $\mathrm{x}$ & & Anthmetical & & $\mathrm{x}$ & $\mathrm{x}$ \\
\hline SFD & See Equation 2 & $\mathrm{x}$ & $\mathrm{x}$ & & & & $\mathrm{x}$ & & \\
\hline
\end{tabular}

Additionally, the normalized Time and Frequency Second Derivative (TFSD) is an indicator that was developed specifically for this study. It represents the time and frequency normalized deviations of each recorded sample. It aims at describing the frequent time variations within specific frequency bands, which are characteristic of tonal or harmonic sounds such as voices or birds. It is calculated as follows:

$$
\operatorname{TFSD}(f, t)=\frac{\left|\frac{d^{2} \mathrm{~L}(\mathrm{f}, \mathrm{t})}{d f d t}\right|}{\sum_{f=31.5 H z}^{f=1}\left|\frac{d^{2} \mathrm{~L}(\mathrm{f}, \mathrm{t})}{d f d t}\right|} \quad \text { Equation 1, }
$$

where $f$ denotes octave bands from $31.5 \mathrm{~Hz}$ to $16 \mathrm{kHz}$.

The Spectral Flatness Deviation (SFD) indicator is also calculated, as it is known to be a good and simple voice activity detector [37]. It describes the standard deviation of the spectral flatness indicator SF, calculated as follows:

$$
S F(t)=\frac{e^{\left(\frac{\sum_{f=31.5 \mathrm{~Hz}}^{f=16 k} \ln (L(f, t))}{10}\right)}}{\frac{\sum_{f=31.5 \mathrm{~Hz}}^{f=16(f, t)}}{10}} \quad \text { Equation 2. }
$$




\subsection{Perceptual data collection}

A questionnaire of 18 11-point bipolar semantic scales on perceptual parameters was administered at each of the 19 assessment locations. The left extremity of the bipolar scale was coded as "1" and its right extremity was coded as " 11 ", the neutral point corresponding to the " 6 " rate. The questions covered the following categories of perceptual parameters, most of them already investigated in previous studies [38]:

- The first category of parameters describes the perception of the previous segment, i.e. the short path that links the assessment location to the previous one:

- The Segment Pleasantness (SP), which describes the pleasantness of the sound environment during the previous segment, from "unpleasant" to "pleasant". Consequently, when the term "segment pleasantness" is used in this study, it refers to the pleasantness of the sound environment of the previous segment of the walking path;

$\circ$ The Change of the Sound environment (CS) describes the perceived change between two assessment locations, from "identical" to "very different";

- The Speed of the Change (SC), which describes the speed of the change described before, from "sudden" to "progressive", when a change was perceived;

- The second category of parameters is related to the overall sound environment at the assessment location:

- The Overall Loudness (OL), which describes the perceived sound level of the sound environment. A scale evolving from "quiet" to "loud" was used;

- The Liveliness (L), which describes if the sound environment appears as alive and animated, from "lifeless" to "lively";

- The Pleasantness (P), which describes the pleasantness of the sound environment, from "unpleasant" to "pleasant". Consequently, when the term "pleasantness" is used in this study, is will refer to the pleasantness of the sound environment at the assessment location;

- The third category of parameters describes the emergent sound sources at the assessment location. The perceived loudness of mopeds (PLM), cars (PLC), horns and sirens (PLH), trucks (PLT) and buses (PLB), were assessed with a scale evolving from "weak" to "loud". Tramways, trains, underground trains, and urban activities were excluded from the study as they were absent from the investigated sound environments.

- The fourth category of parameters deals with the time of presence of sound sources such as traffic $(T)$, voices $(\mathrm{V})$, footsteps $(\mathrm{F})$, birds $(\mathrm{B})$, water $(\mathrm{Wa})$ and wind (Wi). A scale evolving from "rarely present" to "continuously present" was used.

- Finally, a last question describes the visual amenity (VA), from "unpleasant" to "pleasant".

Three additional questionnaires were administered during the study sessions: the participants had to assess the sound pleasantness of the first half of the path (at point 9), the second half of the path (at point 1 or 19 according to the path direction) and the path as a whole (at point 1 or 19 according to the path direction).

\subsection{Procedure}

The four perceptual tests were performed on the Mondays 23/03/2015 and 30/03/2015, between 11 and $12 \mathrm{~h}$ and between 15 and 16h. The path being travelled each day alternated from West to East and from East to West. The global sound level integrated over the path was similar for all the study sessions. Table 3 presents a summary of the study (day and hours of the sessions, direction, number of participants and the global $\mathrm{L}_{\mathrm{A}, \mathrm{eq}}$ integrated over the path). 


\begin{tabular}{lccccc}
\multicolumn{5}{l}{ Table 3 Summary for each study session (day, hour, direction, number of participants, and global measured sound level). } \\
Study session & Day & Hour & Direction & Number of participants & Global path LA,eq \\
\hline S1 & $23 / 03 / 2015$ & $11 \mathrm{~h}-12 \mathrm{~h}$ & East-West & 8 & 72.2 \\
S2 & $23 / 03 / 2015$ & $15 \mathrm{~h}-16 \mathrm{~h}$ & West-East & 11 & 72.0 \\
S3 & $30 / 03 / 2015$ & $11 \mathrm{~h}-12 \mathrm{~h}$ & West-East & 9 & 72.5 \\
S4 & $30 / 03 / 2015$ & $15 \mathrm{~h}-16 \mathrm{~h}$ & East-West & 9 & 72.7 \\
\hline
\end{tabular}

Perceptual data and sound measurements were simultaneously collected at each of the 19 assessment locations, during 3-to-5 minute stops. The duration of each walk was approximately 45 minutes. The meaning of each semantic scale was described to the participants before the study sessions. Then, the participants were asked to keep silent in order not to disturb the sound environment. Special care was taken, by the operator of the recording system, to avoid recording sounds eventually generated near the microphone by the participants or the research team.

\section{Results}

\subsection{Descriptive analysis of the collected data}

\subsubsection{General information}

Concerning the questionnaires to assess the sound environment at each location, six participants (out of 37) carried out very incomplete questionnaires and were discarded from the analysis. Furthermore, assessment location P3 from the second study session (West-East) was removed from the analysis, as it presented very eventful conditions during the assessments (cleaning truck) and two others assessment locations were discarded because of errors on acoustics measurements. Moreover, some incomplete or very erratic answers were eliminated, resulting in a total of 556 valid individual assessments (out of 703), and on 73 (out of 76) valid assessment locations. Concerning the questionnaires to assess part of the paths, 91 individual assessments were finally valid (out of 93).

Multilevel analyses are proposed in our study [39]. They were performed with the package "lme4" in the R Statistical Software. The multilevel analyses presented in this study were performed discerning two levels. The perceptual assessments or physical measurements correspond to the first level. At the second level, there are two random variables: the users and the assessment locations interacting with the four study sessions. The other analyses were performed with the standard package of the R Statistical Software or with the Matlab Statistics Toolbox ${ }^{\mathrm{TM}}$.

\subsubsection{Participant and study session variability}

This section investigates the influence of both the participant and the study session on the perceptual assessments. Figure 3 shows, for the 19 assessment locations and for five parameters (a) the average, calculated over the four study sessions, of the standard deviations of the participant assessments, (b) the standard deviation of the participant assessments averaged over each study session.

Figure 3.a depicts the variability of participant answers, and Figure 3.b shows the variability of the sessions, which can be due to the moment dependence of the assessed sound environments. Pleasantness assessment is affected by both the variability between participants and the variability between study sessions, with an average standard deviation of 1.5 for participants and a standard deviation of 0.7 for study sessions, over the 11-point scale of the pleasantness assessment. Overall loudness assessment is impacted in a similar way, with a average standard deviation of 1.5 for participants and a standard deviation of 0.8 for study sessions. 
In addition, the times of presence of birds and voices show a high variability between study sessions, compared to the other perceptual scales (see Figure 3.b). Nevertheless, when high variabilities are observed, variations in the sound environment can be listened to using the corresponding sound environment recordings, which permitted to assign this variability to the difference in the sound environments and not in the perception.

Finally, some parameters, namely the perceived loudness of buses (PLB) and horns (PLH), the time of presence of water (Wa) and wind (Wi), were almost null for most of the study sessions and showed consequently a very high variability between sessions. Thus, they have been rejected from the analysis. If water sound sources are active factors when one focuses on specific locations such as parks or open squares [40], [41], this effect can probably be neglected when considering very contrasted sound environment at a district scale.
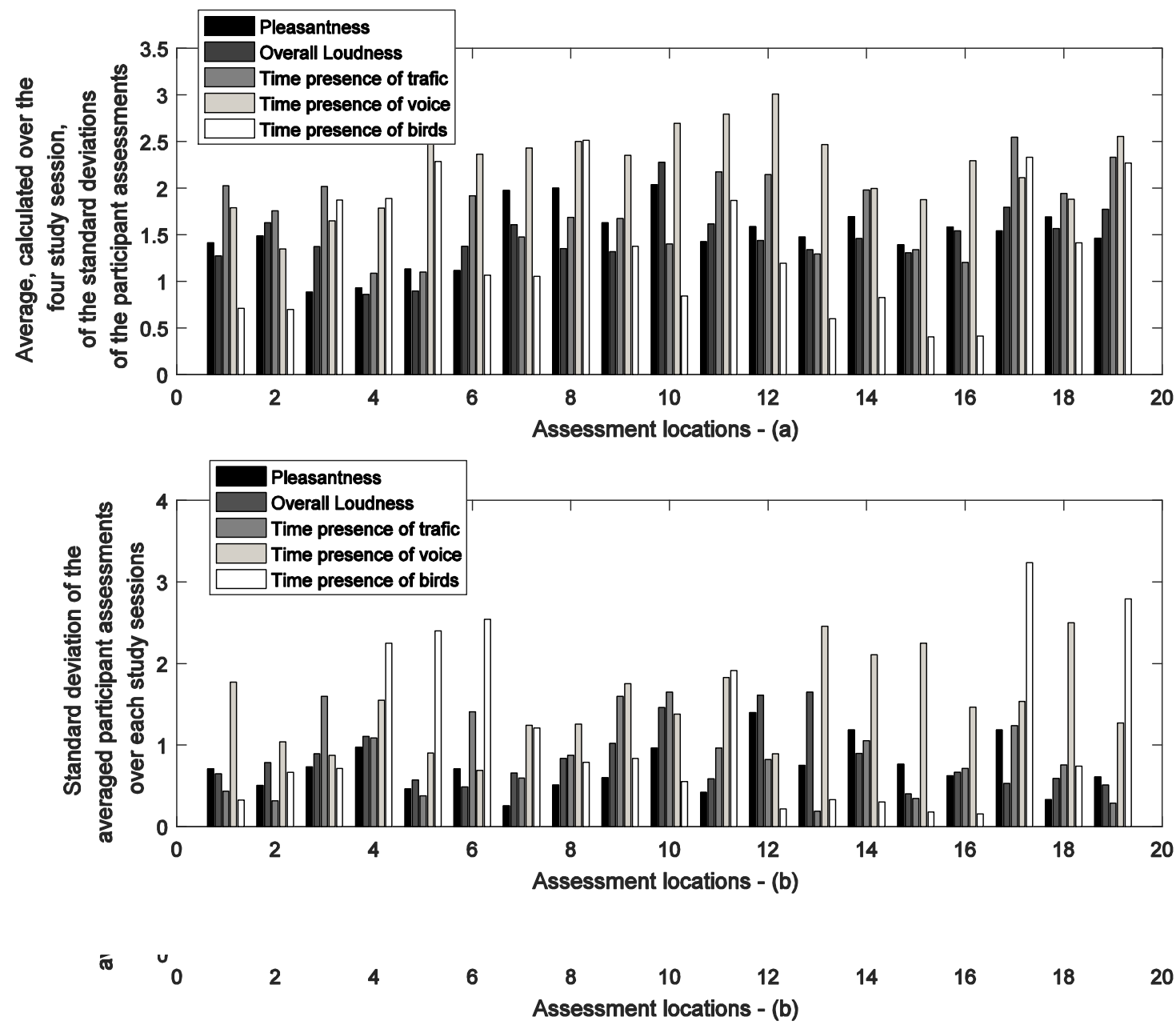

\subsection{Specific location}

\subsubsection{Presentation-order effect}

This section investigates whether or not the perceived pleasantness at an assessment location is influenced by the sound environment experienced immediately before. If this is the case, then additional 
parameters describing the previous experienced sound environment should be included in the pleasantness model of an urban location. Kolmogorov-Smirnov (Matlab Statistics Toolbox ${ }^{\mathrm{TM}}$ ) tests are performed to assess the influence of the direction of arrival that is East-West (EW) or West-East (WE), on the pleasantness assessments for each assessment location. The 556 collected assessments are divided into two groups WE and EW to perform the statistical test. The Kolmogorov-Smirnov test is a non-parametric test of the equality of continuous probability distributions [42].

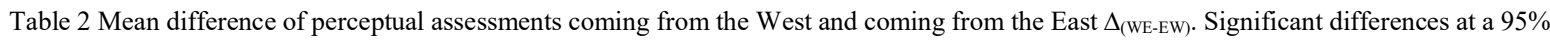
level following the Kolmogorov-Smirnov test are in red.

\begin{tabular}{|c|c|c|c|c|c|c|c|c|c|c|c|c|c|c|c|c|c|c|c|}
\hline & P1 & P2 & P3 & P4 & P5 & P6 & P7 & P8 & P9 & P10 & P11 & P12 & P13 & P14 & P15 & P16 & P17 & P18 & P19 \\
\hline $\mathbf{P}$ & $-0,79$ & $-0,64$ & 0,06 & $-1,06$ & 0,55 & 0,03 & 0,32 & $-0,22$ & $-0,18$ & $-1,19$ & $-0,38$ & 2,00 & 0,00 & 1,43 & 1,02 & $-0,35$ & $-2,06$ & 0,42 & $-0,68$ \\
\hline $\mathbf{L}$ & 20 & 0,85 & $-0,09$ & $-1,39$ & $-0,43$ & $-0,30$ & $-1,16$ & $-1,44$ & $-0,02$ & 0,24 & $-0,68$ & $-0,17$ & 1,53 & 0,67 & $-0,95$ & 0,48 & $-0,35$ & $-0,20$ & $-0,79$ \\
\hline OL & & 67 & $-0,21$ & 1,51 & $-0,57$ & 0,36 & 0,18 & $-0,72$ & $-1,14$ & 0,05 & 0,09 & & 1,25 & $-0,65$ & $-0,35$ & $-0,04$ & 0,90 & $-0,87$ & $-0,34$ \\
\hline PLM & $-0,90$ & $-1,90$ & 0,02 & 1,24 & 0,13 & $-1,50$ & $-0,39$ & $-0,96$ & $-0,38$ & 0,81 & 0,17 & & 3,87 & 0,60 & 1,83 & 1,21 & $-0,39$ & $-0,58$ & 0,63 \\
\hline PLC & $-1,09$ & $-0,66$ & 0,05 & 0,73 & $-0,48$ & 0,90 & $-1,14$ & 0,03 & $-1,07$ & 1,45 & 0,72 & $-0,79$ & 1,04 & 0,49 & $-0,75$ & 0,57 & 0,68 & $-1,22$ & 0,16 \\
\hline LT &, 02 & 2,13 & $-0,32$ & 0,98 & $-0,49$ & 0,70 & 2,91 & 2,42 & 0,61 & 0,73 & $-0,52$ & 0,12 & 0,35 & 1,59 & 0,24 & 2,73 & 1,69 &, 95 & 0,56 \\
\hline PLH & $-1,33$ & $-1,34$ & $-0,03$ & 0,40 & $-0,98$ & $-0,75$ & 2,08 & 0,09 & $-0,12$ & 0,28 & $-0,31$ & 0,00 & 2,60 & 0,89 & 3,03 & 3,82 & 1,02 & 0,76 & 0,57 \\
\hline $\mathbf{T}$ & 0,01 & 0,33 & $-0,47$ & 0,84 & $-0,29$ & 1,96 & 0,14 & 1,24 & $-1,06$ & 1,21 & 1,44 & 0,02 & 0,18 & $-0,46$ & $-0,49$ & 0,48 & 0,17 & $-1,01$ & 0,30 \\
\hline V & 1,79 & $-0,39$ & 1,31 & $-1,31$ & 1,10 & 0,29 & 0,55 & $-0,83$ & $-1,00$ & $-0,44$ & $-0,30$ & 0,24 & 3,24 & 1,82 & $-1,39$ & $-1,41$ & 1,32 & $-3,03$ & $-0,63$ \\
\hline $\mathbf{F}$ & 0,95 & $-1,05$ & $-0,34$ & $-1,47$ & $-2,23$ & $-2,97$ & $-0,73$ & $-1,37$ & $-1,21$ & $-1,29$ & $-2,12$ & $-0,15$ & $-0,29$ & 1,29 & $-1,61$ & $-1,47$ & $-2,71$ & $-2,78$ & $-1,92$ \\
\hline B & $-0,46$ & $-0,81$ & 0,60 & $-3,29$ & $-3,05$ & $-3,37$ & $-2,01$ & $-1,01$ & $-1,15$ & $-0,82$ & $-1,28$ & $-0,20$ & $-0,46$ & 0,13 & $-0,05$ & 0,14 & $-0,47$ & 0,36 & 0,12 \\
\hline VA & $-0,09$ & 0,72 & 1,98 & $-0,32$ & $-0,18$ & 0,72 & $-0,22$ & 1,35 & 1,33 & 0,60 & 1,07 & 2,20 & 0,26 & 0,01 & 0,02 & 0,11 & $-0,37$ & $-2,10$ & $-0,30$ \\
\hline
\end{tabular}

Table 2 gathers the discrepancies, for each parameter, between the two groups and the results of the statistical test. The assessment of the pleasantness differs according to the direction of arrival for only two of the 19 assessment locations of the path:

- The assessments at P12 depend significantly upon the direction of arrival for the pleasantness, but also for the perceived overall level and the visual amenity. These differences are not explained by different sound levels, and an expert listening of the recorded sound files did not allow detecting any acoustic reason. Two hypotheses are formulated:

- The perceived time of presence of mopeds differs between the two directions of arrival $\left(\triangle \mathrm{PLM} \mathrm{(WE}_{(\mathrm{EW})}=-2.11\right)$ at $\mathrm{P} 12$, and could influence the overall loudness or pleasantness estimation in the EW direction [43].

- The visual environment at P12 differs significantly according to the direction of arrival. From East to West a park is in the vision area, while from West to East the participants are facing a dark street which leads straight to a large boulevard. The visual amenity might here thus have had a preponderant effect on the pleasantness assessment, as highlighted already in [44].

- The direction of arrival impacts significantly the perceived pleasantness for the assessment location P17. This point is nearby the noisiest location of the path (the boulevard "Avenue d'Italie" P15, P16). Interestingly, the location P14 shares both the similar characteristics and has the third most important difference $\left(\Delta \mathrm{P}_{(\mathrm{WE}-\mathrm{EW})}=1.43\right)$. Section 3.3.1 will highlight the high change of sound environment around these two assessment locations. This suggests that a location could be perceived more pleasant only if it is associated to a high positive change of sound environment.

In this study, the presentation-order effect has not been evidenced for most of the assessment locations. Thus, the following proposed models for the sound pleasantness of a location will not take this effect into account. 


\subsubsection{Models of pleasantness based on perceptual data}

First, the relationships between the perceptual parameters are investigated. The Pearson's correlation coefficients between perceptual parameters, calculated at the study session scale $(n=73)$, are presented in Table 3.

\begin{tabular}{|c|c|c|c|c|c|c|c|c|c|c|}
\hline & $\mathbf{P}$ & $\mathbf{L}$ & OL & PLM & PLC & PLT & $\mathbf{T}$ & $\mathbf{V}$ & $\mathbf{F}$ & B \\
\hline$\overline{\mathbf{P}}$ & 1,00 & $-0,50 * *$ & $-0,91 * *$ & $-0,74 * *$ & $-0,89 * *$ & $-0,75 * *$ & $-0,86 * *$ & 0,19 & 0,12 & $0,53 * *$ \\
\hline $\mathbf{L}$ & & 1,00 & $0,67 * *$ & $0,31 * *$ & $0,43 * *$ & $0,46^{* *}$ & $0,47 * *$ & $0,43 * *$ & $0,35^{* *}$ & $-0,10$ \\
\hline OL & & & 1,00 & $0,71 * *$ & $0,83 * *$ & $0,73 * *$ & $0,81 * *$ & 0,02 & 0,02 & $-0,44 * *$ \\
\hline PLM & & & & 1,00 & $0,81 * *$ & $0,65 * *$ & $0,74 * *$ & $-0,21$ & 0,02 & $-0,33 * *$ \\
\hline PLC & & & & & 1,00 & $0,74 * *$ & $0,92 * *$ & $-0,26^{*}$ & $-0,10$ & $-0,43 * *$ \\
\hline PLT & & & & & & 1,00 & $0,82 * *$ & $-0,19$ & $-0,07$ & $-0,33 * *$ \\
\hline $\mathbf{T}$ & & & & & & & 1,00 & $-0,22$ & $-0,05$ & $-0,39 * *$ \\
\hline V & & & & & & & & 1,00 & $0,44 * *$ & 0,18 \\
\hline $\mathbf{F}$ & & & & & & & & & 1,00 & $0,42 * *$ \\
\hline B & & & & & & & & & & 1,00 \\
\hline
\end{tabular}

As expected, pleasantness is significantly and negatively correlated with overall loudness $(\mathrm{r}<-0.7)$, and with traffic-related parameters (PLM, PLC, PLT and T).

Liveliness correlates with overall loudness and presents links shared between both human presence (V and $\mathrm{F}$ ), and traffic parameters (T). It seems that this parameter has been interpreted by the participants as a presence of voices, but also traffic.

The presence of birds (B) is positively correlated with pleasantness $(r=0.53)$, and negatively correlated with overall loudness and the presence of traffic $(r=-0.44$ and $r=-0.39)$. Birds are not present or not heard when they are masked by traffic noise.

Consequently, multiple linear regression models are built to estimate the pleasantness at the assessment locations based on perceptual parameters. An additive stepwise optimization is used. When different parameters are proposed as good candidates for the regression model by the procedure, the parameter which is most easily interpretable is preferred. Multi-collinearity among the independent variables is tested by checking the variance inflation factor (VIF). The VIF factor is always lower than 5 for the proposed models in this study, as recommended in [45]. Table 4 presents the different models for perceived pleasantness on the basis of perceptual parameters.

Table 4 Multilevel models of perceived pleasantness from perceptual parameters. Fixed coefficients estimates: regression coefficient (standard errors; t-value), all estimates are significant ( $\mathrm{p}<.05)$; Random parameters: variance components (standard errors); Pseudo $\mathrm{R}^{2}$ statistics; Goodnessof-fit.

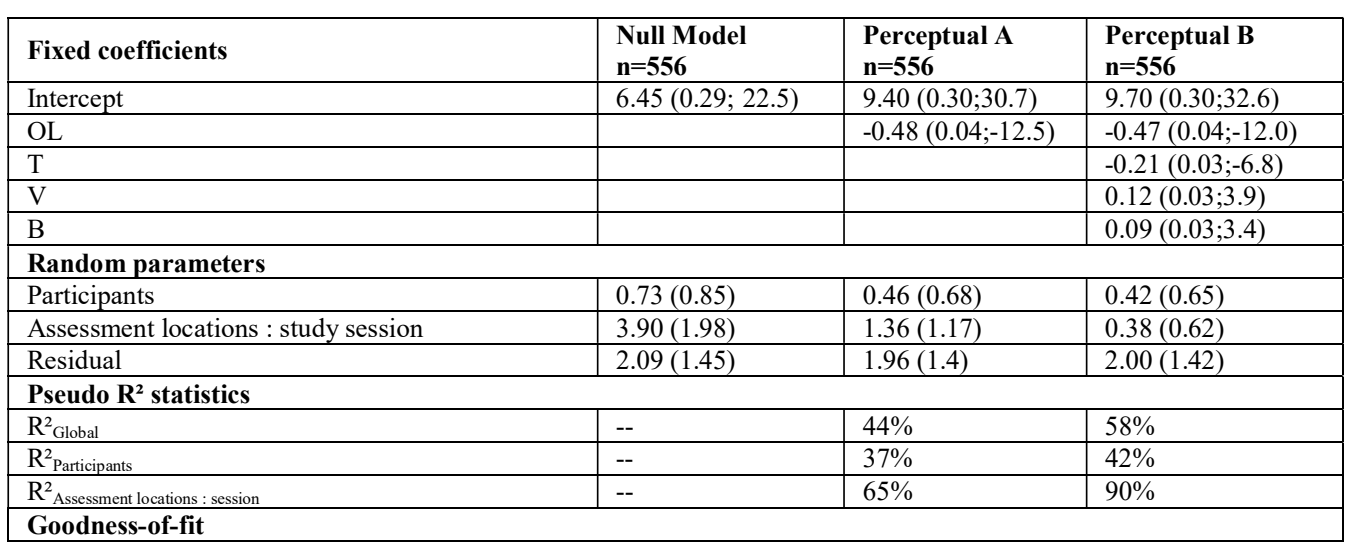




\begin{tabular}{|l|l|l|l|}
\hline Deviance & 2239.8 & 2132.9 & 2072.0 \\
\hline AIC & 2247.8 & 2142.9 & 2088.0 \\
\hline BIC & 2265.1 & 2164.5 & 2122.5 \\
\hline
\end{tabular}

The Pseudo $\mathrm{R}^{2}$ statistics are calculated as follows:

- $\mathrm{R}^{2}$ Global corresponds to the global variance explained by the different models divided by the global variance of the Null Model. The global variance is the sum of the residual variance and the variances associated to the random parameters.

- $\mathrm{R}^{2}$ Participants corresponds to the part of the variance, associated to the participants, explained by the different models compared to the variance, associated to the participants, in the Null Model.

- $\mathrm{R}^{2}{ }_{\text {Assessment locations : session }}$ corresponds to the part of the variance associated to the assessment locations interacting with the study sessions, explained by the different models compared to the variance, associated to the participants, in the Null Model.

The global variance of the "Null Model" is 6.72. The multilevel analysis shows that the variance due to the participants is 0.73 , which represents $11 \%$ of the global variance. The variance due to the change of the sound environment (i.e. the interaction between the four study sessions and the assessment locations) represents $58 \%$ of the global variance. Finally, $31 \%$ of the global variance cannot be explained by any of these random parameters.

Two models of perceived pleasantness on the basis of perceptual parameters are proposed (Perceptual A and Perceptual B). All the goodness-of-fit measures show that Perceptual B model increases significantly the performance compared to the Perceptual A model and that both models increase significantly the performance compared to the Null model.

The multilevel analysis shows that the pleasantness predicted by the unique variable (perceived overall loudness) explains $65 \%$ of the variance due to the change of the sound environment. In addition, overall loudness (OL) has a significant impact on pleasantness, highlighting the tight relation between these two perceptual parameters, already revealed by the Pearson's correlation coefficient between OL and P (Table $3)$.

Four perceptual predictors are selected for the Perceptual B model: overall loudness (OL), times of presence of traffic (T), voices (V) and birds (B). Introducing these additional parameters in the model improves the explained variance due to the change of the sound environment, which reaches now $90 \%$. In this new model, the perceived overall loudness (OL) has the highest regression coefficient highlighting again the tight relation between the two parameters overall loudness and pleasantness. As expected, the time of presence of traffic is associated to a negative regression coefficient. The time of presence of voices and birds are associated to a positive regression coefficient, revealing the already observed positive contribution of natural and human sound sources on pleasantness [46].

However, although very accurate, the models based on perceptual parameters proposed in this section have a low practical potential in a predictive context, since they require prior perceptual tests. Instead, these models highlight the high predictive potential of physical models that would be based on indicators highly correlated to these perceptual parameters OL, T, V and B.

\subsubsection{Models of pleasantness based on physical data}

The Pearson's correlation coefficients between perceptual parameters and physical indicators, calculated at the study session scale $(n=73)$, are given in Table 5 . 
Table 5 Pearson's correlation coefficients $r$ between perceptual parameters and most relevant physical indicators (not significant correlations at a

\begin{tabular}{|c|c|c|c|c|c|c|c|c|c|c|}
\hline & $\mathbf{P}$ & $\mathbf{L}$ & OL & PLM & PLC & PLT & $\mathbf{T}$ & $\mathbf{V}$ & $\mathbf{F}$ & B \\
\hline $\mathbf{L}_{\mathrm{eq}}$ & $-0,65$ & 0,46 & 0,64 & 0,45 & 0,65 & 0,63 & 0,67 & NS & NS & $-0,45$ \\
\hline $\mathbf{L}_{\mathrm{eq}, \mathbf{A}}$ & $-0,74$ & 0,54 & 0,73 & 0,48 & 0,64 & 0,63 & 0,66 & NS & NS & $-0,45$ \\
\hline $\mathbf{L}_{\mathrm{A}, 10}$ & $-0,75$ & 0,51 & 0,75 & 0,47 & 0,66 & 0,59 & 0,66 & NS & NS & $-0,46$ \\
\hline $\mathbf{L}_{\mathbf{A}, \mathbf{5 0}}$ & $-0,79$ & 0,55 & 0,78 & 0,54 & 0,71 & 0,66 & 0,72 & NS & NS & $-0,40$ \\
\hline $\mathbf{L}_{\mathrm{A}, 90}$ & $-0,74$ & 0,53 & 0,72 & 0,45 & 0,62 & 0,60 & 0,62 & NS & NS & $-0,41$ \\
\hline $\mathbf{L}_{10}$ & $-0,66$ & 0,46 & 0,64 & 0,44 & 0,67 & 0,61 & 0,68 & NS & NS & $-0,46$ \\
\hline L50 & $-0,78$ & 0,51 & 0,76 & 0,59 & 0,75 & 0,72 & 0,76 & NS & NS & $-0,44$ \\
\hline $\mathbf{L}_{90}$ & $-0,75$ & 0,49 & 0,72 & 0,55 & 0,68 & 0,66 & 0,69 & NS & NS & $-0,42$ \\
\hline $\mathbf{N}_{10}$ & $-0,76$ & 0,50 & 0,74 & 0,47 & 0,69 & 0,62 & 0,70 & NS & NS & $-0,49$ \\
\hline $\mathbf{N}_{50}$ & $-0,81$ & 0,55 & 0,80 & 0,57 & 0,74 & 0,69 & 0,75 & NS & NS & $-0,43$ \\
\hline $\mathrm{N}_{90}$ & $-0,74$ & 0,53 & 0,72 & 0,48 & 0,63 & 0,62 & 0,64 & NS & NS & $-0,40$ \\
\hline 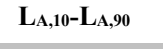 & $-0,28$ & NS & 0,32 & NS & 0,30 & 0,21 & 0,29 & NS & NS & NS \\
\hline SFD & 0,42 & $-0,28$ & $-0,42$ & $-0,21$ & $-0,28$ & $-0,21$ & $-0,27$ & NS & NS & NS \\
\hline TFSD $_{500 \mathrm{~Hz}}$ & NS & NS & NS & NS & $-0,27$ & $-0,26$ & $-0,32$ & 0,53 & NS & NS \\
\hline TFSD $_{1 \mathrm{kHz}}$ & 0,48 & NS & $-0,38$ & $-0,46$ & $-0,58$ & $-0,56$ & $-0,63$ & 0,41 & NS & NS \\
\hline TFSD $_{2 \mathrm{kHz}}$ & 0,59 & $-0,35$ & $-0,53$ & $-0,39$ & $-0,55$ & $-0,44$ & $-0,55$ & NS & NS & 0,68 \\
\hline TFSD $_{4 \mathrm{kHz}}$ & 0,46 & NS & $-0,42$ & $-0,34$ & $-0,43$ & $-0,29$ & $-0,38$ & NS & NS & 0,76 \\
\hline TFSD $_{4 k H z(1 / 8 s)}$ & 0,53 & NS & $-0,43$ & $-0,41$ & $-0,52$ & $-0,31$ & $-0,45$ & NS & NS & 0,81 \\
\hline $\mathbf{L}_{50,63 \mathrm{~Hz}}$ & $-0,76$ & 0,47 & 0,69 & 0,59 & 0,77 & 0,71 & 0,79 & NS & NS & $-0,36$ \\
\hline $\mathbf{L}_{50,125 \mathrm{~Hz}}$ & $-0,81$ & 0,54 & 0,77 & 0,62 & 0,79 & 0,76 & 0,83 & NS & NS & $-0,42$ \\
\hline $\mathbf{L}_{50,250 \mathrm{~Hz}}$ & $-0,83$ & 0,50 & 0,78 & 0,65 & 0,82 & 0,76 & 0,83 & $-0,25$ & NS & $-0,47$ \\
\hline $\mathbf{L}_{50,500 \mathrm{~Hz}}$ & $-0,85$ & 0,57 & 0,84 & 0,60 & 0,77 & 0,72 & 0,77 & NS & NS & $-0,49$ \\
\hline $\mathrm{L}_{50,1 \mathrm{kHz}}$ & $-0,86$ & 0,59 & 0,85 & 0,61 & 0,77 & 0,71 & 0,78 & NS & NS & $-0,51$ \\
\hline $\mathbf{L}_{50,2 \mathrm{kHz}}$ & $-0,79$ & 0,54 & 0,78 & 0,52 & 0,71 & 0,64 & 0,72 & NS & NS & $-0,48$ \\
\hline $\mathrm{L}_{50,4 \mathrm{kHz}}$ & $-0,61$ & 0,46 & 0,60 & 0,34 & 0,50 & 0,49 & 0,52 & NS & NS & $-0,25$ \\
\hline
\end{tabular}

The indicator with highest correlation to both Pleasantness and Overall Loudness is $\mathrm{L}_{50}$ within the 1 $\mathrm{kHz}$ octave band: $\mathrm{L}_{50,1 \mathrm{kHz}}$. Interestingly, $\mathrm{N}_{10}, \mathrm{~L}_{\mathrm{A}, 50}$ and $\mathrm{L}_{50}$ also show higher correlations with $\mathrm{OL}$ and $\mathrm{P}$ than the more classically used $\mathrm{L}_{\mathrm{A}, \mathrm{eq}}$ and $\mathrm{L}_{\mathrm{eq}}$. This is in line with previous urban and rural soundscape studies, which already highlighted the limitations of the $\mathrm{L}_{\mathrm{eq}}$ [8], [11], [29], [30].

The perceptual parameters related to traffic, namely PLM, PLC, PLT and T, correlate well with $\mathrm{L}_{50}$ from $63 \mathrm{~Hz}$ to $250 \mathrm{~Hz}$. This can be explained by the high proportion of low frequency sound generated by road traffic, compared to the other sources that compose urban sound environments.

As expected, the time of presence of birds (B) correlates negatively with the traffic-related parameters. The physical indicator which best correlates with (B) is the $\mathrm{TFSD}_{\text {mean, } 4 \mathrm{kHz}}$, for $125 \mathrm{~ms}$ measurements $(\mathrm{r}=.81)$ or for $1 \mathrm{~s}$ measurements $(\mathrm{r}=.76)$. This shows the potential of this simple indicator to identify the presence of birds in an urban environment. Similarly, the physical indicator which best correlates with the time of presence of voices is the $\mathrm{TFSD}_{\text {mean, } 500 \mathrm{~Hz}}(\mathrm{r}=.53)$. This highlights the potential of the proposed TFSD indicators to identify and classify the urban sound environments based on their source composition without the use of more complex algorithms. Table 6 presents the different models of perceived pleasantness based on physical parameters. 
Table 6. Multilevel models of perceived pleasantness from physical parameters. Fixed coefficients estimates: regression coefficient (standard errors; t-value), all estimates are significant ( $\mathrm{p}<.05)$; Random parameters: variance components (standard errors); Pseudo $\mathrm{R}^{2}$ statistics; Goodnessof-fit.

\begin{tabular}{|c|c|c|c|}
\hline Fixed coefficients & $\begin{array}{l}\text { Null Model } \\
\mathrm{n}=556\end{array}$ & $\begin{array}{l}\text { Physical A } \\
\text { n=556 }\end{array}$ & $\begin{array}{l}\begin{array}{l}\text { Physical B } \\
\text { n=556 }\end{array} \\
\end{array}$ \\
\hline Intercept & $6.45(0.29 ; 22.5)$ & $20.71(0.97 ; 21.3)$ & $16.48(1.6 ; 10.3)$ \\
\hline$L_{50,1 \mathrm{kHz}}$ & & $-0.28(0.02 ;-15.0)$ & $-0.25(0.02 ;-12.5)$ \\
\hline$T F S D_{\text {mean }, 500 H z}$ & & & $15.82(6.62 ; 2.4)$ \\
\hline$T F S D_{\text {mean }, 4 \mathrm{kHz}(1 / 8 \mathrm{~s})}$ & & & $16.82(6.84 ; 2.5)$ \\
\hline \multicolumn{4}{|l|}{ Random parameters } \\
\hline Participants & $0.73(0.85)$ & $0.82(0.90)$ & $0.86(0.93)$ \\
\hline Assessment locations : session & $3.90(1.98)$ & $0.73(0.86)$ & $0.59(0.77)$ \\
\hline Residual & $2.09(1.45)$ & $2.07(1.44)$ & $2.07(1.44)$ \\
\hline \multicolumn{4}{|l|}{ Pseudo $\mathbf{R}^{2}$ statistics } \\
\hline $\mathrm{R}_{\text {Global }}^{2}$ & -- & $46 \%$ & $48 \%$ \\
\hline $\mathrm{R}^{2}$ Participants & -- & $-12 \%$ & $-17 \%$ \\
\hline $\mathrm{R}^{2}$ Assessment locations : session & -- & $82 \%$ & $85 \%$ \\
\hline \multicolumn{4}{|l|}{ Goodness-of-fit } \\
\hline Deviance & 2239.8 & 2139.4 & 2129.7 \\
\hline $\mathrm{AIC}$ & 2247.8 & 2149.4 & 2143.7 \\
\hline $\mathrm{BIC}$ & 2265.1 & 2171.0 & 2173.9 \\
\hline
\end{tabular}

Multiple linear regression models are built to estimate the pleasantness at assessment locations based on physical indicators. Two models of the perceived pleasantness based on physical parameters are proposed, Physical A and Physical B. The physical indicators that best correlate with the perceptual parameters are selected. The goodness-of-fit measures show that both models increase significantly the performance compared to the Null model. Even if positive, the contribution of Physical B compared to Physical A is more contrasted. However, an ANOVA analysis (R - Package stats) shows that both models are significantly different $(\mathrm{F}(2,554)=8.65, \mathrm{p}<.001)$, increasing the global explained variance from $46 \%$ to $48 \%$.

The Physical A model relies on the parameter $\mathrm{L}_{50,1 \mathrm{kHz}}$ only. The multilevel analysis shows that this parameter explains $82 \%$ of the variance in perceived pleasantness due to change in the sound environment. $\mathrm{L}_{50,1 \mathrm{kHz}}$ is a significant variable for the prediction of pleasantness (Table 6). The lower explained variance, compared to Physical B, relates to the fact that the perceptual parameters and the physical indicators (here OL and $\mathrm{L}_{50,1 \mathrm{kHz}}$ ) are not perfectly correlated (Table 5).

The Physical B model is built by introducing the physical parameters which are best correlated with the perceived times of presence of traffic, voices and birds. However, $\mathrm{L}_{50,250 \mathrm{~Hz}}$ (for traffic) is rejected because it is collinear with $\mathrm{L}_{50,1 \mathrm{kHz}}(\mathrm{VIF}>5$ ). The multilevel analysis shows that model Physical B explains $85 \%$ of the variance of the perceived pleasantness variance due to the change of the sound environment. Introducing $\mathrm{TFSD}_{\text {mean, } 4 \mathrm{kHz}(1 / 8 \mathrm{~s})}$ and $\mathrm{TFSD}_{\text {mean, } 500 \mathrm{~Hz}}$ in the regression improves the perceived pleasantness estimates. In this new model, $\mathrm{L}_{50,1 \mathrm{kHz}}$ is the indicator with the strongest influence on the pleasantness estimation.

\subsubsection{Applying the models in a cartography context}

In this section, the results given by the proposed models are averaged over the assessment locations. Then, they are compared to the average pleasantness values given by participants at the same locations. Applying the models at this scale $(\mathrm{n}=19)$ mimics a static sound environment mapping context. In order to assess the predictive power of the different models, the Pearson's correlation coefficients between the average of measured and predicted pleasantness, as well as the Root Mean Square Errors (RMSE), are presented in Table 6 . 
Table 6 Pearson's correlation coefficients $r$ and RMSE values averaged over the assessment locations, between the prediction by the four proposed models and the perceptual pleasantness assessment.

\begin{tabular}{llll} 
Model & Parameters & r & RMSE \\
\hline Perceptual B & OL,T,V,B & $0.98^{* *}$ & 0.63 \\
Perceptual A & OL & $0.95^{* *}$ & 1.18 \\
Physical B & $\mathrm{LL}_{50, \mathrm{lkHz}}, \mathrm{TFSD}_{\text {mean, } 500 \mathrm{~Hz}}, \mathrm{TFSD}_{\text {mean, } 4 \mathrm{kHz}(1 / 8 \mathrm{~s})}$ & $0.97 * *$ & 0.53 \\
Physical A & $\mathrm{L} 50, \mathrm{kkHz}^{* *}$ & $0.96^{* *}$ & 0.62 \\
\hline
\end{tabular}

Figure 4 depicts the averaged pleasantness predicted at each assessment location, by the different models. The four models proposed in this study allow very accurate pleasantness estimation $(r>0.9$ and RMSE < 1.2). Moreover, introducing sound source characteristics of the sound environment, such as voices and birds in this study, improves significantly the estimates, especially in quiet places (as for points P3, P4 and P5) and near schoolyards (as for point P10). Nevertheless, the proposed models overestimate the pleasantness of the noisiest sound environments, here located on two main boulevards (points P1, P2, $\mathrm{P} 15$ and P16). 


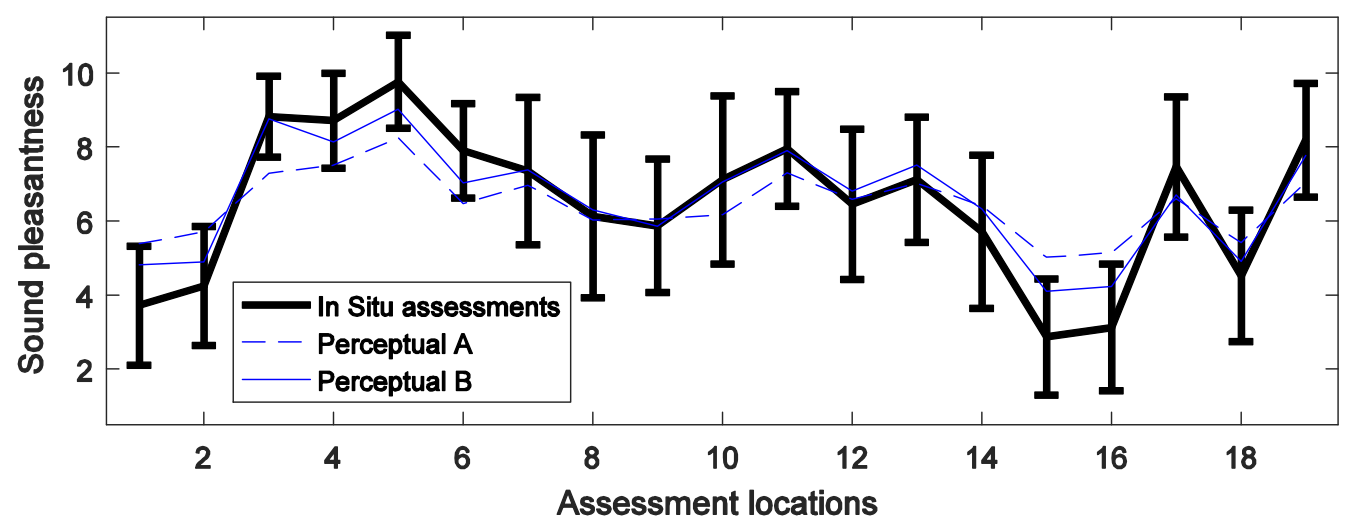

(a)

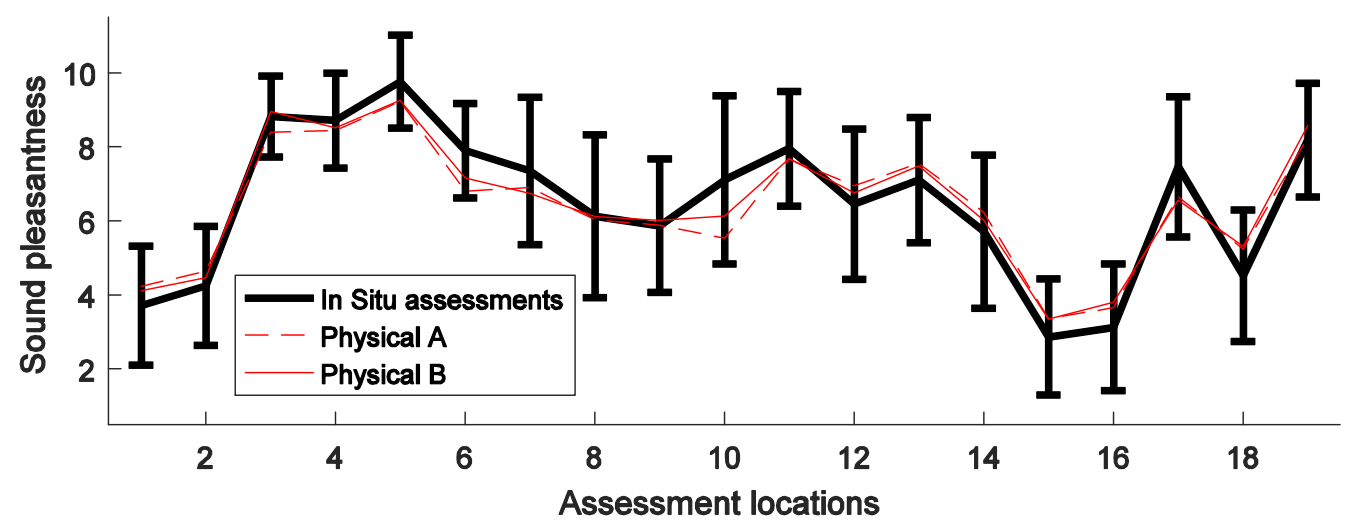

(b)

Figure 4. Mean pleasantness assessed (black thick line, with standard error deviation) and predicted by the proposed models: (a) perceptual models, (b) physical models.

\subsection{Path assessment}

\subsubsection{Short path assessments}

Kolmogorov-Smirnov tests (Matlab Statistics Toolbox ${ }^{\mathrm{TM}}$ ) are performed to assess the influence of the direction of the walk that is East-West (EW) or West-East (WE), on the segment pleasantness (SP). Segments are the short path between two consecutive assessment locations, with an average length of 115 meters (1-3 min of duration). The collected assessments are divided into two groups WE and EW to perform the statistical test.

Table 7 Mean differences of the segment perceived pleasantness assessed after walk from West to East and assessed after walk from East to West $\Delta \mathrm{SP}_{(\mathrm{WE}-\mathrm{EW})}$, and perceived change of sound environment (SC). The differences which are significant at $95 \%$ level following the KolmogorovSmirnov test are in red.

\begin{tabular}{|c|c|c|c|c|c|c|c|c|c|c|c|c|c|c|c|c|c|c|}
\hline & $\mathbf{S}_{\mid 1-2]}$ & $\mathbf{S}_{[2-3]}$ & $\mathbf{S}_{|3-4|}$ & $\mathbf{S}_{[4-5]}$ & $\mathbf{S}_{[5-6]}$ & $S_{[6-7]}$ & $\mathbf{S}_{[7-8]}$ & $\mathbf{S}_{[8-9]}$ & $\mathbf{S}_{[9-10]}$ & $\mathbf{S}_{[10-11]}$ & $\mathbf{S}_{[11-12]}$ & $\mathbf{S}_{[12-13]}$ & $\mathbf{S}_{[13-14]}$ & $\mathbf{S}_{[14-15]}$ & $\mathbf{S}_{[15-16]}$ & $\mathbf{S}_{[16-17]}$ & $\mathbf{S}_{[17-18 \mid}$ & $\mathbf{S}_{|18-19|}$ \\
\hline$\Delta \mathbf{S P}$ & $-0,83$ & $-3,26$ & $-0,61$ & $-0,24$ & 2,05 & 0,43 & 1,12 & 0,72 & $-0,62$ & $-1,54$ & 1,35 & 0,62 & 1,33 & 1,63 & $-0,52$ & $-2,84$ & 0,10 & $-1,62$ \\
\hline SC & 3,5 & 8,7 & 5,3 & 5,4 & 6,3 & 3,2 & 6,7 & 4,6 & 8,1 & 6,5 & 5,9 & 5,6 & 4,9 & 8,2 & 2,5 & 8,8 & 6,2 & \\
\hline
\end{tabular}


Table 7 gathers the discrepancies, for each perceptual parameter, between the two groups. The pleasantness assessments for segments $S_{[2-3]}$ and $S_{[16-17]}$ are the only ones that are significantly dependent on the walking direction. Both segments are also the ones with the highest perceived change in the sound environment ( $\mathrm{SC}=8.7$ and 8.8). In fact, the perceived change in the sound environment (SC) and the mean deviation of the perceived pleasantness for the segments $(\Delta \mathrm{SP})$ correlate significantly $(\mathrm{r}=.65, \mathrm{p}<0.005)$. This suggests that the segment assessment depends on its walking direction, which might be explained by a recency effect. Such effects were shown in recent works about transitions between different sound environments [36], or about the temporal dynamics of sound environments and their assessment [33].

The Segment Pleasantness (SP) is then estimated using the sound environments assessed at the two assessment locations situated at each end point of the given segment $\left(\mathrm{P}_{\text {start }}\right.$ and $\left.\mathrm{P}_{\text {end }}\right)$. The proposed model explains $83 \%$ of the variance $\left(\mathrm{R}^{2}=.83, \mathrm{~F}(2,70)=167, \mathrm{p}<.001\right)$. Equation 7 presents the corresponding model.

$$
S P=0.82+0.21 * P_{\text {start }}+0.69 * P_{\text {end }} \quad \text { Equation } 3
$$

The standardized regression coefficient related to $\mathrm{P}_{\text {end }}\left(\mathrm{b}^{*}=.80, \mathrm{t}(70)=15.22, \mathrm{p}<.001\right)$ is much higher than $\mathrm{P}_{\text {start }}\left(\mathrm{b}^{*}=.23, \mathrm{t}(70)=4.44, \mathrm{p}<.001\right)$. Again, this highlights the influence of the walking direction on the assessment of the pleasantness of segments that lasted between 1 to 3 minutes.

\subsubsection{Long path assessments}

Predicting the pleasantness of an urban walk trip has many potential interests, such as informing a pedestrian about the potential restorative capacity of even health benefit related to his/her intended walk, or optimizing the related route choice through specific algorithms [47]. Figure 5 presents the relation between the pleasantness assessments of a path globally assessed, and the pleasantness averaged over the locations that were assessed along this path, for the global route and both halves of the route.

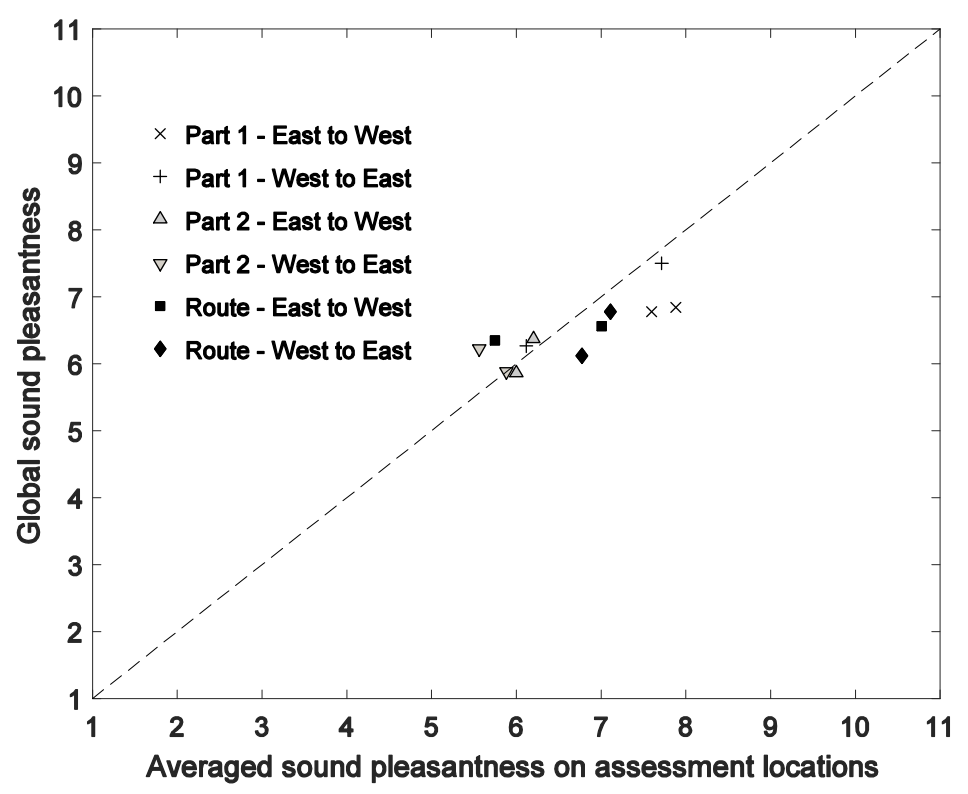

Figure 5 Mean global pleasantness, relatively to both halves of the path (Part 1, Part 2) and the route as a whole (Route), and the pleasantness averaged on assessment locations following the 4 study sessions $(n=12), r=0.8, p<0.005$. 
No recency effect is observed in this analysis, although the global path end points ( $\mathrm{P} 1, \mathrm{P} 9$ and $\mathrm{P} 19)$ have very different sound environments. In addition, there is a strong correlation between the pleasantness values averaged on the assessment locations and the global pleasantness assessment $(r=.8, p<0.005)$. This suggests that averaging the pleasantness assessed at each assessment location sampled regularly along the global path can be a good estimator of the pleasantness of a global path lasting more than 20 minutes.

\section{Discussion}

Section 3.2.2 suggests that liveliness was probably interpreted by the participants as a presence of voices, but also traffic. This interpretation differs from previous studies that showed that liveliness is better related to soundscapes with a dominant presence of voices [11], [29]. This difference might be due to the fact that in [11], [29], the participants had to choose the dominant source, while here each sound source is assessed. This might also result from the translation of the French word "Animé" (in English "Liveliness"), which is maybe a wider concept in French than in English. Liveliness is also negatively but weakly correlated with pleasantness $(r=-0.5)$. This is not completely in line with [11] which found liveliness uncorrelated with pleasantness. Finally, even if a large variety of urban sound environments were encountered by the participants during the proposed pathway (Table 1), the chosen methodology restricted the range of possible stimuli as compared to the above mentioned studies. This might be a reason for the observed discrepancies.

Interestingly, the model of pleasantness based on perceptual parameters in this study, Perceptual B, is very similar to the one proposed by Ricciardi et al. [8], which is written as follows:

$$
\mathrm{P}=8.11-0.38 * \mathrm{OL}-0.14 * \mathrm{~T}+0.20 * \mathrm{~V}+0.15 * \mathrm{~B} \quad \text { Equation } 4
$$

The two studies used the same semantic differential questionnaire and were conducted in the same districts in Paris, but relied on a different corpus of locations and participants and were separated in time by more than two years. This tends to prove the robustness of these simple linear regression models, based on the perceived Overall Loudness and the time of presence of typical urban sound sources, to estimate the pleasantness of sound environments. Even if the methodologies differed, similar comparisons can be drawn with other recent studies. For example, Axelsson et al. showed similar Pearson's correlation coefficients between perceived pleasantness and indicators such as $\mathrm{L}_{\mathrm{Aeq}}$ or $\mathrm{N}_{10}$ and the models they proposed also included parameters such as the predominance of technological, human and natural sources [11].

Models that estimate the perceived pleasantness of the sound environment were constructed with perceptual or physical predictors. The decrease in the predictive power of pleasantness estimates, from the perceptual parameters to the physical indicators $(85 \%$ of the variance due to the change of the sound environments, instead of $90 \%$ ), suggests that better pleasantness models could be proposed if physical indicators, more closely related to the perceptual parameters, were used. Unfortunately, the classic energetic, temporal and spectral indicators fail to accurately describe these perceptual parameters. Thus, further research should focus on physical parameters that allow identifying each given sound source, or characterizing each relevant perceptual parameter.

Adding the fixed coefficients does not significantly influence the residual variance (about $30 \%$, Table 4 and 6). It can be assumed that this variance is related to the very detailed 11-point scale that is used for the assessment; one can expect that this variance would remain if a given participant had to assess several times the same sound environment. 
At the path-scale, the Pearson's correlation coefficients between assessed and predicted perceived pleasantness from physical parameters reaches 0.97 with a very small mean square error $(0.53$ on an 11 point scale). Using this model with physical indicators extracted from low-cost sensor networks, or participative measurements, would allow mapping pleasantness. This type of map would probably be easier to understand than the standardized noise map that shows the sound levels on a decibel scale.

The presentation-order effect has not been evidenced for most of the assessment locations. Very strong changes in the sound environment may however have a significant impact on perceived pleasantness, but there are not enough sudden changes in the study. Further studies with better controlled conditions, as one would obtain in laboratory experiments, should be designed to specifically investigate the presentationorder effect on pleasantness assessments in an urban context.

This study also offers an insight into the retrospective pleasantness assessment of urban walks. For very short walks between two assessment locations, a recency effect is shown to occur and the pleasantness of the path can be predicted from the pleasantness of the two end points that delimit the path. Nevertheless, this recency effect does not appear when larger routes are assessed.

On the basis of these insights, a number of hypotheses can be proposed:

- The duration taken to assess one segment or a complete path differs. In the case of a path assessment, each participant makes the effort to remember the whole path and its different assessed locations, to finally average its appreciation of the path. In the case of a single segment, the response given by a participant might be more instinctive and his answer less sensitive to any cognitive bias.

- The recency effect on the pleasantness appreciation might depend, in an urban context, on the walk duration. Short walks might give rise to a strong recency effect for the segment assessment; but this recency effect tends to disappear with longer walks.

- For long paths, the recency effect tends to disappear because the succession of positive transitions (walking towards a better sound environment) and negative transitions (walking towards a worse sound environment) could lead to a cancellation of this effect.

Nevertheless, in this research, only twelve long path assessments are studied and thus these observations should be handled with care. Others studies with a methodology specially constructed for testing these three hypotheses is now required to investigate the recency effect during a typical urban walk trip as, for example, presented in [48].

\section{Conclusion}

The main conclusions of the present research are:

1) Multiple linear regression models based on perceptual parameters, such as the overall loudness, the time of presence of traffic, birds and voice, can successfully describe the perceived pleasantness of the sound environment.

2) A simple indicator based on the time and frequency second derivative (TFSD) is proposed, which is best correlated, among a large set of calculated physical indicators, with the perceived time presence of birds and voices.

3) Multiple linear regression models based on physical parameters such as $\mathrm{L}_{50,1 \mathrm{kHz}}, \mathrm{TFSD}_{\text {mean, } 500 \mathrm{~Hz} \text {, }}$ $\mathrm{TFSD}_{\text {mean, } 4 \mathrm{kHz}(1 / 8 \mathrm{sec})}$ are able to describe the average perceived pleasantness of the sound 
environment. Introducing physical indicators that represent the presence of birds and voices in the modeling significantly improves the estimation.

4) A multilevel analysis reveals that about $58 \%$ of the global variance is due to the context and about $11 \%$ is due to the participants.

5) For very short paths between two assessment locations, pleasantness can be predicted from the pleasantness of the two end points that delimit the walk.

Additional studies are needed to investigate the influence of recency effects during urban walks of various durations more in detail, and to study the influence of both the transitions and the presentation order effect, on path pleasantness assessments. Also, this study suggests that an improvement of the pleasantness models could be obtained if physical indicators, more closely related to the perceptual parameters, were found.

\section{Acknowledgments}

This work was carried out in the framework of the GRAFIC project, supported by the French Environment and Energy Management Agency (ADEME) under contract No. 1317C0028.

\section{References}

[1] EC, "Directive 2002/49/EC of the European parliament and the Council of 25 June 2002 relating to the assessment and management of environmental noise," Off. J. Eur. Communities, vol. 189, no. 12, pp. 12-25, 2002.

[2] F. Aletta, J. Kang, and Ö. Axelsson, "Soundscape descriptors and a conceptual framework for developing predictive soundscape models," Landsc. Urban Plan., vol. 149, no. FEBRUARY, pp. 65-74, May 2016.

[3] A. Can, G. Guillaume, and B. Gauvreau, "Noise Indicators to Diagnose Urban Sound Environments at Multiple Spatial Scales," Acta Acust. united with Acust., vol. 101, no. 5, pp. 964 974, Sep. 2015.

[4] B. Berglund, P. Hassmén, and A. Preis, "Annoyance and Spectral Contrast Are Cues for Similarity and Preference of Sounds," J. Sound Vib., vol. 250, no. 1, pp. 53-64, 2002.

[5] C. Lavandier and B. Defréville, "The contribution of sound source characteristics in the assessment of urban soundscapes," Acta Acust. united with Acust., vol. 92, no. 6, pp. 912-921, 2006.

[6] F. Aletta, E. Margaritis, J. Kang, R. Singh, D. Botteldooren, and Ö. Axelsson, "Soundscape mapping in the urban context: a case study in Sheffield," in AESOP 2015, 2015.

[7] J. Kang and B. Schulte-Fortkamp, Soundscape and the Built Environment, CRC Press. CRC Press, 2015.

[8] P. Ricciardi, P. Delaitre, C. Lavandier, F. Torchia, and P. Aumond, "Sound quality indicators for urban places in Paris cross-validated by Milan data," J. Acoust. Soc. Am., vol. 138, no. 4, pp. $2337-$ 2348, Oct. 2015.

[9] D. Botteldooren, C. Lavandier, A. Preis, D. Dubois, I. Aspuru, C. Guastatavino, L. Brown, M. Nilsson, and T. C. Andringa, "Understanding urban and natural soundscapes," in Forum Acousticum 2011, 2011.

[10] M. E. Nilsson, D. Botteldooren, and B. De Coensel, "Acoustic Indicators of Soundscape Quality 
and Noise Annoyance in Outdoor Urban Areas," in 19th International Congress on Acoustics, 2007.

[11] O. Axelsson, M. E. Nilsson, and B. Berglund, "A principal components model of soundscape perception,” J. Acoust. Soc. Am., vol. 128, no. 5, p. 2836, Nov. 2010.

[12] I. García Pérez, I. Aspuru Soloaga, K. Herranz-Pascual, and I. García-Borreguero, "Validation of an indicator for the assessment of the environmental sound in urban places," in Euronoise 2012, 2012.

[13] L. Brocolini, C. Lavandier, M. Quoy, and C. Ribeiro, "Measurements of acoustic environments for urban soundscapes: choice of homogeneous periods, optimization of durations, and selection of indicators.," J. Acoust. Soc. Am., vol. 134, no. 1, pp. 813-821, 2013.

[14] P. Delaitre, C. Lavandier, C. Ribeiro, M. Quoy, E. D’Hondt, E. Gonzalez Boix, and K. Kambona, "Influence of loudness of noise events on perceived sound quality in urban context," Inter Noise, pp. 1-10, 2014.

[15] M. R. Ismail, "Sound preferences of the dense urban environment: Soundscape of Cairo," Front. Archit. Res., vol. 3, no. 1, pp. 55-68, Mar. 2014.

[16] C. Lavandier and B. Defreville, "The contribution of sound source characteristics in the assessment of urban soundscapes," Acta Acust. united with Acust., vol. 92, no. 6, pp. 912-921, Nov. 2006.

[17] L. Yu and J. Kang, "Factors influencing the sound preference in urban open spaces," Appl. Acoust., vol. 71, no. 7, pp. 622-633, 2010.

[18] G. R. Watts, R. J. Pheasant, and K. V Horoshenkov, "Predicting perceived tranquillity in urban parks and open spaces," Environ. Plan. B Plan. Des., vol. 38, no. 4, pp. 585-594, Jul. 2011.

[19] J. Y. Jeon, P. J. Lee, J. Y. Hong, and D. Cabrera, "Non-auditory factors affecting urban soundscape evaluation.," J. Acoust. Soc. Am., vol. 130, no. 6, pp. 3761-70, Dec. 2011.

[20] P. Lindborg, "Correlations between personality traits and physiological and perceptual responses to soundscapes," in International Conference on Music Perception and Cognition, 2012.

[21] M. Raimbault, C. Lavandier, and M. Bérengier, "Ambient sound assessment of urban environments: Field studies in two French cities," Appl. Acoust., vol. 64, no. 12, pp. 1241-1256, 2003.

[22] K. Filipan, M. Boes, D. Oldoni, B. De Coensel, and D. Botteldooren, "Soundscape quality indicators for city parks, the Antwerp case study," in Forum Acusticum 2014, 2014.

[23] N. Maisonneuve, M. Stevens, M. E. Niessen, and L. Steels, "NoiseTube: Measuring and mapping noise pollution with mobile phones," Environ. Sci. Eng. (Subseries Environ. Sci., pp. 215-228, 2009.

[24] A. Can, L. Dekoninck, and D. Botteldooren, "Measurement network for urban noise assessment: Comparison of mobile measurements and spatial interpolation approaches," Appl. Acoust., vol. 83, pp. 32-39, Sep. 2014.

[25] P. H. T. Zannin, M. S. Engel, P. E. K. Fiedler, and F. Bunn, "Characterization of environmental noise based on noise measurements, noise mapping and interviews: A case study at a university campus in Brazil," Cities, vol. 31, pp. 317-327, Apr. 2013.

[26] P. Mioduszewski, J. A. Ejsmont, J. Grabowski, and D. Karpiński, "Noise map validation by continuous noise monitoring," Appl. Acoust., vol. 72, no. 8, pp. 582-589, Jul. 2011.

[27] G. Rey Gozalo, J. Trujillo Carmona, J. M. Barrigón Morillas, R. Vílchez-Gómez, and V. Gómez 
Escobar, "Relationship between objective acoustic indices and subjective assessments for the quality of soundscapes," Appl. Acoust., vol. 97, pp. 1-10, 2015.

[28] A. Bockstael, B. De Coensel, P. Lercher, and D. Botteldooren, "Influence of temporal structure of the sonic environment on annoyance," in 11th International Congress on Noise as a Public Health Problem (ICBEN), 2011.

[29] M. E. Nilsson, "Soundscape quality in urban open spaces," in Inter-Noise, 2007.

[30] B. De Coensel and D. Botteldooren, "The quiet rural soundscape and how to characterize it," Acta Acust. united with Acust., vol. 92, no. 6, pp. 887-897, 2006.

[31] M. E. Nilsson and B. Berglund, "Soundscape quality in suburban green areas and city parks," Acta Acust. united with Acust., vol. 92, no. 6, pp. 903-911, 2006.

[32] G. Brambilla and L. Maffei, "Responses to Noise in Urban Parks and in Rural Quiet Areas," Acta Acust. united with Acust., vol. 92, no. 6, pp. 881-886, Oct. 2006.

[33] J. Steffens and C. Guastavino, "Trend Effects in Momentary and Retrospective Soundscape Judgments," Acta Acust. united with Acust., vol. 101, no. 4, pp. 713-722, Jul. 2015.

[34] J. Maillard and A. Kacem, "Evaluation de la Qualité Acoustique des Parcours Piétonniers Urbains par Auralisation," in CFA 2016, 2016.

[35] S. Kuwano and S. Namba, "Continuous judgment of level-fluctuating sounds and the relationship between overall loudness and instantaneous loudness," Psychol. Res., vol. 47, no. 1, pp. 27-37, Apr. 1985.

[36] P. Delaitre and C. Lavandier, "Representation of the acoustic contrast in urban context through noise mapping," in Inter-Noise, 2012.

[37] R. Venkatesha Prasad, A. Sangwan, H. S. Jamadagni, M. C. Chiranth, R. Sah, and V. Gaurav, "Comparison of voice activity detection algorithms for VoIP," in Proceedings ISCC 2002 Seventh International Symposium on Computers and Communications, 2002, pp. 530-535.

[38] L. Brocolini, C. Lavandier, C. Marquis-Favre, M. Quoy, and M. Lavandier, "Prediction and explanation of sound quality indicators by multiple linear regressions and artificial neural networks," Acoustics 2012. pp. 2121-2126, 23-Apr-2012.

[39] K. Robson and D. J. Pevalin, Multilevel Modeling in Plain Language, vol. 2015. SAGE Publications Ltd, 2015.

[40] M. Rådsten Ekman, P. Lundén, and M. E. Nilsson, "Similarity and pleasantness assessments of water-fountain sounds recorded in urban public spaces," J. Acoust. Soc. Am., vol. 138, no. 5, pp. 3043-3052, Nov. 2015.

[41] J. Y. Jeon, P. J. Lee, J. You, and J. Kang, "Perceptual assessment of quality of urban soundscapes with combined noise sources and water sounds.," J. Acoust. Soc. Am., vol. 127, no. 3, pp. 13571366, 2010.

[42] W. W. Daniel, Applied nonparametric statistics. PWS-Kent Publ., 1990.

[43] J. Morel, C. Marquis-Favre, D. Dubois, and M. Pierrette, "Road Traffic in Urban Areas: A Perceptual and Cognitive Typology of Pass-By Noises," Acta Acust. united with Acust., vol. 98, no. 1, pp. 166-178, Jan. 2012.

[44] S. Viollon, C. Lavandier, and C. Drake, "Influence of visual setting on sound ratings in an urban environment," Appl. Acoust., vol. 63, no. 5, pp. 493-511, May 2002. 
[45] V. A. Micheal and A. A. Abiodun, "Estimation of Regression Coefficients in the Presence of Multicollinearity," Soc. Basic Sci. Res. Rev., vol. 2, no. 10, pp. 404-415, 2014.

[46] B. De Coensel, S. Vanwetswinkel, and D. Botteldooren, "Effects of natural sounds on the perception of road traffic noise," J. Acoust. Soc. Am., vol. 129, no. 4, p. EL148, 2011.

[47] A. Can, T. Van Renterghem, and D. Botteldooren, "Exploring the use of mobile sensors for noise and black carbon measurements in an urban environment," Acoustics 2012. 23-Apr-2012.

[48] P. Aumond, A. Can, B. De Coensel, D. Botteldooren, C. Ribeiro, and C. Lavandier, "Sound pleasantness evaluation of pedestrian walks in urban sound environments," ICA 2016, 22nd International Congress on Acoustics. p. 11p, 05-Sep-2016.

\begin{tabular}{|c|c|c|c|c|c|c|c|c|c|}
\hline \multirow[b]{2}{*}{ Abbreviation } & \multirow[b]{2}{*}{ Description } & \multicolumn{2}{|c|}{$\begin{array}{l}\text { Integration } \\
\text { time }\end{array}$} & \multicolumn{2}{|c|}{ Ponderation } & \multirow{2}{*}{\multicolumn{2}{|c|}{$\begin{array}{c}\text { Standar } \\
\text { d } \\
\text { deviatio } \\
\text { n }\end{array}$}} & \multirow[b]{2}{*}{$\begin{array}{c}\text { Min, Max } \\
\text { Percentiles } \\
(1,5,10,50, \\
90,95,99)\end{array}$} & \multirow[b]{2}{*}{$\begin{array}{c}\begin{array}{c}\text { Octave } \\
\text { band } \\
\text { from }\end{array} \\
31.5 \mathrm{~Hz} \text { to } \\
16 \mathrm{kHz}\end{array}$} \\
\hline & & & $125 \mathrm{~ms}$ & $\begin{array}{c}\text { Linear } \\
\text { ponderation }\end{array}$ & A ponderation & & & & \\
\hline $\mathbf{L}$ & Sound pressure level & $\mathrm{x}$ & $\mathrm{x}$ & $\mathrm{x}$ & $\mathrm{x}$ & Equivalent $\left(\mathrm{L}_{\mathrm{eq}}\right)$ & $\mathrm{x}$ & $\mathrm{x}$ & $\mathrm{x}$ \\
\hline $\mathbf{N}$ & $\begin{array}{l}\text { Zwicker loudness } \\
\text { (sone), (ISO } 532 \text { B) }\end{array}$ & $\mathrm{x}$ & $\mathrm{x}$ & & & & & $\mathrm{x}$ & \\
\hline $\begin{array}{c}\mathrm{L}_{10}-\mathrm{L}_{90}, \mathrm{~L}_{5}-95 \\
\mathrm{~N}_{10}-\mathrm{N}_{90}, \sigma\end{array}$ & $\begin{array}{l}\text { Dispersion parameters } \\
\sigma: \text { standard deviation } \\
\text { of sound pressure level }\end{array}$ & $\mathrm{x}$ & $\mathrm{x}$ & $\mathrm{x}$ & $\mathrm{x}$ & & & & $\mathrm{x}$ \\
\hline $\begin{array}{c}\mathrm{CoG}_{32 \mathrm{~Hz}-8 \mathrm{kHz}} \\
\mathrm{CoG}_{125 \mathrm{~Hz}-8 \mathrm{kHz}} \\
\mathrm{CoG}_{32 \mathrm{~Hz}-16 \mathrm{kHz}}\end{array}$ & $\begin{array}{l}\text { Spectrum center of } \\
\text { gravity }\end{array}$ & $\mathrm{x}$ & & $\mathrm{x}$ & & Arithmetical & & $\mathrm{x}$ & \\
\hline $\begin{array}{c}N N E_{L>70 d B(A)} \\
N N E_{L>75 d B(A)} \\
N N E_{L>80 d B(A)} \\
N N E_{L>L 10 d B(A)} \\
N N E_{L>L A e q, T+10} \\
d B(A) \\
N N E_{L>L A e q, T+15} \\
d B(A)\end{array}$ & $\begin{array}{l}\text { Number of Noise } \\
\text { Events }\end{array}$ & $\mathrm{x}$ & & & $\mathrm{x}$ & & & & \\
\hline $\begin{array}{c}M I_{L>70 \mathrm{~dB}(\mathrm{~A})} \\
\mathrm{MI}_{\mathrm{L}>75 \mathrm{~dB}(\mathrm{~A})} \\
\mathrm{MI}_{\mathrm{L}>80 \mathrm{~dB}(\mathrm{~A})} \\
\mathrm{MI}_{\mathrm{L}>\mathrm{L} 10 \mathrm{~dB}(\mathrm{~A})} \\
\mathrm{MI}_{\mathrm{L}>\mathrm{LAeq}, \mathrm{T}+10 \mathrm{~dB}(\mathrm{~A})} \\
\mathrm{MI}_{\mathrm{L}>\mathrm{LAeq}, \mathrm{T}+15 \mathrm{~dB}(\mathrm{~A})}\end{array}$ & $\begin{array}{c}\text { Mask Index } \\
\text { (cumulative time during } \\
\text { which thresholds are } \\
\text { exceeded) }\end{array}$ & $\mathrm{x}$ & & & $\mathrm{x}$ & & & & \\
\hline TFSD & See Equation 1 & $\mathrm{x}$ & $\mathrm{x}$ & $\mathrm{x}$ & & Arithmetical & & $\mathrm{x}$ & $\mathrm{x}$ \\
\hline SFD & See Equation 2 & $\mathrm{x}$ & $\mathrm{x}$ & & & & $\mathrm{x}$ & & \\
\hline
\end{tabular}

